\title{
Female Labor Force Participation under COVID-19 Pandemic:Evidence from the first round of the Uganda High-frequency Phone Survey on COVID-19
}

Mukoki James ( $\square$ jammy.mukoki@gmail.com )

College of Business \& Management Sciences (COBAMS) Makerere University, Kampala (Uganda) https://orcid.org/0000-0002-3043-7479

Candia Andabati Douglas

Makerere University, Kampala

Ssebulime Kurayish

National Planning Authority-Uganda (NPA)

Musoke Edward

Makerere University, Kampala

Research Article

Keywords: Female Labor Force Participation, COVID-19 Threat, lockdown, Coronavirus outbreak

Posted Date: October 20th, 2020

DOI: https://doi.org/10.21203/rs.3.rs-94798/v1

License: (c) (i) This work is licensed under a Creative Commons Attribution 4.0 International License.

Read Full License 


\title{
Female Labor Force Participation under COVID-19 Pandemic:
}

\section{Evidence from the first round of the Uganda High-frequency Phone Survey on COVID-19}

\author{
Mukoki James', \\ jammy.mukoki@gmail.com

\begin{abstract}
The outbreak of the novel coronavirus that causes COVID-19 disease has taken the world by storm, given the containment measures better known as the Standard Operating Procedures (SOPs), including strict or mild lockdowns and social distancing measures. The impact of these aggregated measures have caused not only loss of lives but also financial, economic, social and even political unrest around the world and Uganda has not been spared either, given its weak economic and health care system (UBOS 2020). This study thus was designed to investigate the impact of COVID-19 lockdown measures and its associated self-reported threat on the female labor force participation $(F L F P)$ in Uganda following the March $20^{\text {th }} 2020$ shutdown of the economy by the government. The interest in women in this study stems from the fact that despite economic activity shutdown, women's work and roles extend beyond their office space to their home. Therefore using the first round of the Uganda High-Frequency Phone Survey on COVID-19 (UHFS) dataset conducted by Uganda Bureau of Statistic (UBOS) following the lockdown measure, our results indicates a $17 \%$ reduction in FLFP in the early days of the economic shutdown. We further find larger impacts of lockdown on female labor force participation in extreme cases where both partners are under locked down. These impacts are more pronounced among women with children as opposed to those without children. Conversely our results indicates larger impacts of lockdown among those with initial conditions of unemployment prior to the outbreak than those who were employed in time following the pandemic outbreak. We see our results as being consistent with the famous household labor theories. Our results point to the need for preferential treatment for women to encourage and enhance their labor market participation in times of pandemic. Lastly social programs targeting particularly women should be designed and implemented under the ministry of Gender Labor and Social Development.
\end{abstract}

Keywords: Female Labor Force Participation, COVID-19 Threat, lockdown, Coronavirus outbreak

JEL Classification: J01, J13, J16, J21

${ }^{1}$ Corresponding author 


\section{Introduction}

The origins of Coronavirus Disease 2019 (COVID-19) can be traced to Wuhan, a city in a central province of China. The disease is believed to have been caused by a novel coronavirus known to epidemiologists as severe acute respiratory syndrome (SARS-CoV-2) virus (Mckibbin and Fernando 2020). With its first epicenter in china, COVID-19 quickly spread around the world like wildfire at the start of 2020 which caught the attention of the World Health Organization (WHO)

to declare it a global pandemic of international concern. This was very important to enable governments around the world to coordinate efforts in response to the pandemic. The impact of COVID-19 on the global economy has been immense and more pronounced in developing countries like Uganda beyond, i.e. just mortality and morbidity concerns. For instance there have been interruptions in the production and global supply chains, given the fact that much of transportation systems were halted as a measure to curb the spread of the disease. According to (Mckibbin and Fernando 2020; Titan et al. 2020) the pandemic has caused some turmoil and panic among the global business community which has caused household consumption and employment distortions affecting household purchasing power.

As a result of the pandemic outbreak, the IMF projected the global economy to contract by 3 percentage points in 2020, a rescaling of Global growth rates from 2.9 to 2.4, while that of SubSaharan region will shrink by 1.6 percentage points, a rescaling Africa's growth from 3.2 percent to 1.8 percent (UNECA, 2020). In the same vein the international Labor Organization (ILO) projected a Global job loss of 10.5 percent with Africa and the America's being the most affected followed by the Pacific and Asian countries 70 and 22 percent respectively. The impact of the pandemic in Uganda has been visible, for instance, According to (Lakuma et al. 2020), it was projected that if the pandemic persists for six months, about 3.8 million workers would lose their jobs and that over $75 \%$ of urban workers were projected to lose their jobs permanently. Given the 
impact that the pandemic has had on the growth sectors of the economy such as the services, agriculture and manufacturing sectors, the National Planning Authority (NPA) anticipated a 3 to 4 percentage points growth rates moving forward from the previous 5.2 percent recorded for the last five years and that this reduction might spillover into the next financial year (Mukiza 2020).

In response to the pandemic outbreak, the Ugandan government was swift in the early stages of the disease, and instituted strict containment measures as early as $18^{\text {th }}$ of March 2020 even without a single case reported by then. Such measures among others included local and international travel restrictions including banning of public transport and closure of international airport, a 14 day quarantine was instituted for those suspected to have the disease, international and local conferences and gatherings including religious, weddings and musical concerts and shows were banned in an effort to disperse crowds to ensure social distancing. Eight days after Uganda reported its first COVID-19 case, the president on $30^{\text {th }}$ of March declared a national curfew that was to run from $7 \mathrm{pm}$ to $6: 30 \mathrm{am}$. These strict containment measures helped the country to avert the catastrophe that awaited it, this because any increase in infections would have overwhelmed the national healthcare system which is under developed and underfunded. In addition the fear factor in the early days of the pandemic also played a crucial role forcing people to obey the Standard Operating Procedures (SoPs) instituted by the Ministry of Health (MoH) for the fear of loss of lives as witnessed in developed countries like Italy, Spain and the United States of America. Despite the effectiveness of some of those strict measures on the spread of the novel coronavirus, it is extremely important to understand how these measures had an impact on the different dimensions of the household particularly their likelihood to participate in the labor market and its impact on the general household welfare as the crisis evolves.

There is no doubt the pandemic has caused havoc around the world for instance by the time of writing this paper, the world had accumulated a total of 28.3 million cases, with 19.1 million 
recoveries and 913,000 death with United states having the most cases in the world and India and Brazil following closely in the second and third places respectively (John Hopkins University, 2020). In Uganda the total cumulative cases by $12^{\text {th }}$ of September stood at 3,776 , with 1,741 recoveries and 44 deaths. Such impressive diseases management results has seen those responsible for the fight against COVID-19 and the president of Uganda receive praises from international community and from the World Health Organization for the good job well done on the containment of the pandemic which as averted a disaster in Uganda (MOH, 2020). The aim of this study was to there to analyze the impact COVID-19 lockdown on the female labor force participation in Uganda.

\subsection{Motivation of the study.}

The motivation of studying female labor force participation during the pandemic as it evolves is that effective sector targeted policies can be designed to tackle the negative effects of the pandemic on the household and the economy at large. Secondly according to Human Rights Watch, by $23^{\text {rd }}$ July 2020, 12 people had been killed by security forces enforcing COVID-19 related containment with only one case confirmed by then. Thirdly forced coexistence due to lockdown of the economy lead to increase in domestic violence. For instance lockdown and the curfew have meant that families members are now forced to stay together in a limited space this has caused a rise in domestic violence and child abuses including rape and which have unfortunately resulted into isolated incidences of death across the country, given the fact that for many women and children staying at home exposes them to danger. Other pandemic related studies have reported similar results (see; (Arenas-Arroyo, Fernandez-Kranz, and Nollenberger 2020; Gaudecker et al. 2020) Our study aims at analyzing the impact of COVID-19 related containment measures on female labor force participation given the fact that women's time is divided between employment and home production, there is an assertion that women's time and work at home instead increased 
under the pandemic thus we aim at testing this notion. Secondly the paper will also document the impact of income loss since the lockdown was instituted on the working parents and its ripple impact on the household's food security. Thirdly the study will also explain the linkages between job loss, home schooling or remote learning as welfare as household food security. And lastly the study will incorporate heterogeneity anticipated between these relationships particularly across regions, gender and income groups among household members both employed and those unemployed.

In order to answer the questions raised in this paper, we make use of National wide Pandemic monitoring survey known as the HFPS on COVID-19 that was carried out by Uganda Bureau of Statistics (UBOS) during the period of June 2020-May 2021 under the support of the World Bank to enable countries to effectively monitor the pandemic as it evolves. Using this dataset we are able to compare employment status, income loss and food security of households including time for homecare for both working and non-working women during the pandemic period.

This study contributes to the literature in a number of ways. First we analyze the impact of forced homestay (lockdown) on economic stress (income loss) and labor participation of women using a real time pandemic evolving high-quality data set. Given the fact the UHFPS on COVID-19 is based on Uganda National Panel Survey (UNPS) samples, we make use of pre-COVID-19 variables to endogenous for the initial conditions for working household members. Second, we explore the relationship between food security and work with special attention given to time allocation on home care and remote learning of children. Lastly, we analyze the burden of COVID19 along gender and residence dimensions. Understanding these inter-relationships is important because it aids in the development of sector specific policies and measures to mitigate and reduce both short and long run negative impact of the disease on women in particular. 


\section{Literature review}

There is already an established and still growing body of literature on the economic impact of health related pandemics and epidemics on economic performance and growth of any nation. Particularly health economists use population vital statistics such as child and maternal mortality and life-expectancy to study the impact of pandemic outbreak on the performance of the economy. For example studies on earlier pandemics found a positive impact of the above measures on the economic welfare and growth (Bloom and Sachs, 1998, Bhargava and et al., 2001). More recent studies on the COVID-19 have analyzed the impact of the pandemic on different dimensions of human life at both macro and micro levels for instance on firms performance in Italy (Balduzzi et al. 2020), cost of school closures (Psacharopoulos et al. 2020), Price Adjustment during the COVID-19 Pandemic (Balleer et al. 2020), Intimate Partner Violence under forced lockdown (Arenas-Arroyo, Fernandez-Kranz, and Nollenberger 2020) and Mental Health in the Time of COVID-19 (Tani et al. 2020). Other COVID-19 related studies include (Angelucci et al. 2020; Gaudecker et al. 2020; Gershuny et al. 2020; Goff et al. 2020; Shin, Kim, and Koh 2020; Snower 2020).

The world has experienced a number of pandemics of a varying catastrophic proportions ranging from HIV/AIDS, Severe acute respiratory syndrome (SARS) and pandemic influenza with the deadliest being the 1918-19 Spanish influenza (Mckibbin and Fernando 2020). According to the burden of the disease literature, there are several ways that a pandemic can impact the economy which is either direct or indirect (cost of illness) that results into economic burden. The traditional analysis of disease burdens has been to rely on the death and morbidity records to estimate loss of future productivity due to lost lives and disability. However it has been said that these conventional methods of estimating the economic impacts of a pandemic which has no vaccination like in cases of HIV/AIDS and SARS underestimates the impacts. This provides a basis of deep thinking of 
how to analyze the impact of COVID-19 pandemic as it evolves since the disease may not end anytime soon. According to Haacker (2004), diseases such as AIDS which has lived with humans for close to four decades has affected households, governments and businesses through constraints on labor markets, loss of livelihoods and increased private and public sector costs on treatment and care for disabled persons and disadvantaged children. Despite the damaging impacts of AIDS, there have been treatments and preventive measures that have minimized the risks associated with the diseases and a number of studies have documented this success at a macro level (see Haacker, 2004). Another macro level study by Bloom et al. (2005) on the analysis of the global impacts of mutation of avian influenza strain finds that open economics are the most affected with high rate exposure to international shocks, from his scenario simulations Global GDP and trade in goods and services contracts by $0.6 \%$ and $14 \%$ respectively.

In a more recent study on the impact of COVID-19 on the education sector, (Goff et al. 2020) used a within- subject comparison method on the survey data collected from college students just before and after the pandemic hit the United States of America to gauge their market attitude, they find that there was a significant decline in the support for markets just before the pandemic started. In their study, students thought that the markets were less likely to be affected and more likely to cause harm to their future predicted income earnings. In Addition they also find support to increase by the size of the government although this increase was found not to translate into redistributive policy particularly like minimum wage and food stamps in the case of the USA. In a similarly study to estimate the cost of school closures by (Psacharopoulos et al. 2020), their results estimates indicate that indeed school closures reduce future earnings of students according to the level of education and that this effect is larger for developing countries, perhaps due to under developed system of healthcare to treat the sick and efficiently respond to emergencies. However their estimates are limited and very conservative in generality since they assumed only four months of 
school closure in the USA, other countries like Uganda for example have had more than four months of school closure with other countries like Kenya declaring a school dead year due to the surging number of COVID-19 cases. It has been estimated that COVID-19 pandemic has affected $90 \%$ of the learners around the globe.

Gaudecker et al. (2020) in their study on the impact of COVID-19 Pandemic on work in the Netherlands finds that economic welfare programs limited the impact of the pandemic on the job market in the early stages of the pandemic and thus work from home increase as a substitute for officer work. A closely related study comes from South Korea where (Shin, Kim, and Koh 2020) estimated the economic impact of a targeted response COVID-19 program in Seoul. Their results indicate an increase in foot traffic and also a decrease in retail sales within a limited distance of the program but that this recovered to its pre-pandemic levels just after four weeks. They conclude that well-designed measures and pin-point targeted measures can be less costly initiatives as recovery measures lifting the lockdowns. A study by (Snower 2020) has found a big distortion in demand and supply in the markets due to COVID-19 which she calls the Great Economic Mismatch, this has made governments in terms of stimulus packages to get the economies back on their feet futile. in an Italian study on the impact of COVID-19 on firms and their access to credit, (Balduzzi et al. 2020) finds that credit constraints exacerbated the effects on factor demand and sales, and that firms that were credit constrained charged high prices that affected their customer base and thus their bottom line. They also argue that both supply and demand shocks experienced during such a pandemic either shape or distort the firm's plans in terms of production and market target with supply being aggregately more important. A similar study by (Balleer et al. 2020) in German analyses the price setting behavior during the pandemic to understand the role of demand and supply under economic interruptions. They find that both demand and supply forces coexist but demand shortages are more pronounced than supply in the short-run. The pressure to decrease 
price during the pandemic up to $11 \%$ also worsens the impact of COVID-19, their study calls for an effective price stabilization policy such as demand stabilization to act as a buffer against the implications of the pandemic.

At micro level, the impact of the pandemic has been analyzed by (Arenas-Arroyo, FernandezKranz, and Nollenberger 2020) on the effect of COVID-19 on intimate partner violence (IPV) under economic shutdown conditions, using an online survey, their results indicate a $23 \%$ increase in IPV, and that the impact of economic consequence is a large as that of the lockdown. In addition the effect worsens if the position of men is threatened within the household (Titan et al. 2020). On the other hand, results from an online time use survey from the UK by (Gershuny et al. 2020) find that there was a substantial reduction in risk activities with high exposure to the novel coronavirus and corresponding increase in low risk behavior and increase in standard operating procedures (SOPs). Lastly a study in the UK used the UK Household Longitudinal Study (UKHLS) to analyze the impact of the pandemic on the household income security and its consequences on the mental well-being, the argument here was that women experienced competing demands on their time both at work place, work at home and child care. They find that mental health was worsening for working mothers than their non-working mother counterparts and the disease burden on the mental health greatly varies by gender and wealth quintile (Tani et al. 2020). Therefore any pandemic response policies should incorporate such varying inequalities in the society.

\section{Methods and Materials}

\subsection{Data sources}

The study makes use of the dataset from the recent Uganda High-frequency Phone Survey on COVID-19 (UHFS) conducted by Uganda Bureau of Statistics (UBOS) in June of 2020. This survey is the first round of high-frequency phone survey of households that was initiated to track 
the impact of COVID-19 Pandemic on Ugandan households on a month to month basis for one years during the pandemic period. The survey is part of the effort by the World Bank to support countries around the world in data collection to enable the monitoring of the pandemic as it evolves with funding from the United States Agency for International Development (USAID). The survey is part of the World Bank's Living Standards Measurement Study (LSMS) program that is responsible for similar data collections for many countries across the globe. In the first phase of UHFS, a total of 2,257 households out of 2,421 households that were previously interviewed in the 2019/2020 Uganda National Panel Survey (UNPS) were contacted and successfully interviewed accounting for 93\% response rate (UBOS 2020). The goal was to carry out more 11 rounds to similar interviews as the pandemic evolved. Uganda National Panel Survey (UNPS) being nationally representative data, HFPS samples had their weights and calibrations calculated based on UNPS frameworks. Mainly for two reasons first; counteract selection bias and second to mitigate against response bias caused by not interviewing UNPS households without phones and phone numbers respectively.

The first round of data collection upon which this study is based took place for a total of two weeks starting on June 3rd 2020. Information was gathered on the different dimensions of social and economic interactions under the pandemic. The data collected include Updated Household roaster, Knowledge regarding the spread of COVID-19, Behavior and social distancing, households' access to services and other necessities, respondent's employment Information on Agriculture, Income loss Food insecurity experience scale, concerns of head of the household on COVID-19, Coping strategies and Safety nets (UBOS 2020). The interest of this study will be on the employment sector of the survey.

The main purpose of UHFS is to enable the government of Uganda to monitor the socio-economic impacts of the pandemic and the containment measures associated with it (UBOS 2020). The 
beauty with this kind of survey is that it follows the COVID-19 pandemic as it evolves in a real time scenario, such information is valuable to health workers and government national COVID19 task force to design effective policies and standard operating procedures to mitigate the negative impacts of the pandemic.

\subsection{Description of the outcome variable}

The outcome variable is employment status, captured as a dichotomous variable, where those employed took on $1(F L F P=1)$ and unemployed took a zero $(F L F P=0)$ during the pandemic. Secondly a change in the employment is also studied to account the impact of the pandemic on the labor force participation. Other variables of interest include sector of employment and revenue fluctuations on businesses to capture the impact on self-account workers.

\subsection{Estimation strategy}

We are interested in analyzing the impact of COVID-19 on the labor market outcomes in Uganda during the pandemic related containment measures such as lockdowns, with particular attention paid to female labor force participation. This is because women face competing demands on their time both at the workplace and at home on child care. To achieve this goal, we follow a formulation similar to (Arenas-Arroyo, Fernandez-Kranz, and Nollenberger 2020) and estimate the following regression equation based on a probit regression model for economically active women aged 1854 years. The reduced form is

$$
F L F P_{\text {lockdowni }}=\beta_{0}+\beta_{1} H C_{i}+\sum_{i} \beta_{i} X_{i}+\varepsilon_{i}
$$

Where, $L F P_{\text {lockdowni, }}$, represents the outcome variable pertaining to female labor force participation for women I during the COVID-19 lockdown, $H C_{i}$ is an indicator of a working mother engaged in household child care during the lockdown, this includes home schooling for remote learning pupils and students and child care. Vector $X_{i}$ includes both individual and household 
characteristics that are assumed to also affect the likelihood of participating in the labor market by a woman. The variables contained in vector $X_{i}$ included age, marital status, presence of child, household size, education, gender, household income status, residence, religion, other labor market activities during COVID-19, lockdown variables and jobless variables are all dummy in nature. We assume at any point in time during the pandemic, either mother, father or both parents are locked down thus we incorporate dummy for parents lockdown donated as PLDi.

Incorporating all the variables in equation (1) above, the following expanded model is estimated in the first phase:

$F L F P_{\text {lockdowni }}=\beta_{0}+\beta_{1} H C_{i}+\beta_{2 i}$ COVID. $19_{\text {threat }}+\beta_{3} P_{L} D_{\text {Male }}+\beta_{4} P L D_{\text {Female }}+$ $P L D_{\text {Both }}+\varphi L F P_{\text {Before CovID } / 19}+\sigma_{i} D O I_{i}+\rho_{i} X_{i}+\gamma_{i} Z_{i}+\varepsilon_{i}$

Where vector $Z_{i}$ represents partners' characteristics and $L F P_{B e f o r e}$ controls for labor participation status before the onset the pandemic to avoid multi-collinearity between $L P F$ and household and individuals characteristics, $X$ we control for the date of the interview $D O I$ to capture the intensity of the responses as the pandemic evolves. Economic stress is captured by COVID-19, which was captured by asking whether people thought the outbreak of the pandemic posed an economic threat.

The data was analyzed using STATA Version 14, a descriptive summary for female labor force participation is done controlling for lockdown, and second we carried out binary analysis using the famous Pearson's chi-square test this was done purposely to identify variables that have some association with the outcome variable of interest. Significant variables and those deemed to be important in explaining the outcome variable are advanced to the next level for subsequent analysis. Lastly we fit a probit model at 5\% level of significance. These results and more are reported in the results section below. 


\subsection{Results and Discussions}

\section{Descriptive Statistics}

\begin{tabular}{|l|l|l|l|l|}
\hline Category & Age & Frequency & Percent & Worked last week \\
\hline Boys & $<18$ years & 516 & 22.88 & \\
\hline Girls & $<18$ years & 528 & 23.41 & \\
\hline Men & $>18$ years & 574 & 25.45 & $\begin{array}{l}\text { No }=179 \\
\text { Yes }=395\end{array}$ \\
\hline Women & $>18$ years & 637 & 28.25 & $\begin{array}{l}\text { No }=210 \\
\text { Yes }=427\end{array}$ \\
\hline Total & & $\mathbf{2 , 2 5 5}$ & $\mathbf{1 0 0 . 0 0}$ & $\mathbf{1 , 2 1 1}$ \\
\hline
\end{tabular}

Sources: Author's Computations based on UHFS (2020) Survey

From table 1: above the survey in wave 1 interviewed a total of $\mathbf{2 , 2 5 5}$ individuals with women taking on the largest number, our unit of analysis are the women who made up $28.25 \%$ of the total individuals during the pandemic. And further analysis from this point on words is focused on women with comparison with their male counterparts in reference to their participation in the labor markets during the COVID-19 outbreak. Clearly more women worked last week prior to the survey than men at the same time more women did not work than as seen from the fourth column of table 1 above.

Table 2: The impact of COVID-19 lockdown on female labor market participation

\begin{tabular}{lllll}
\hline Panel & \multicolumn{1}{c}{ Variables } & FLFP & No-FLFP & Run a business \\
\hline 1 & Female parent locked down (PLD_female) & $0.0712^{*}$ & $-0.136^{* * *}$ & $0.135^{*}$ \\
& & $(0.039)$ & $(0.090)$ & $(0.076)$ \\
2 & Male parent locked down (PLD_male) & $0.204^{* * *}$ & $-0.517^{* * *}$ & -0.034 \\
& & 0.060 & $(0.144)$ & $(0.105)$ \\
3 & Both parents locked down (PLD_both) & $-0.243^{* *}$ & $0.565^{* * *}$ & 0.063 \\
& & $(0.098)$ & $(0.206)$ & $(0.187)$ \\
4 & COVID-19 Pose high threat & $-0.324^{* * *}$ & $0.744^{* * *}$ & $-0.339^{*}$ \\
& & 0.086 & $(0.286)$ & $(0.180)$ \\
5 & $-.253^{* *}$ & $0.538^{*}$ & $-0.358^{*}$ \\
& COVID-19 Pose moderate threat & $(0.120)$ & $(0.294)$ & $(0.186)$ \\
\hline Number of Obs & 427 & 210 & 1209 \\
Mean dependent variable & 0.670 & 0.174 & 0.580 \\
SD dependent variable & 0.478 & 0.379 & 0.494 \\
Regional fixed effects & No & No & No \\
Date or interview control & No & No & No \\
Pre-COVID-19 employment status & Yes & Yes & Yes \\
\hline
\end{tabular}

Sources: Author's Computations based on UHFS (2020)

Notes: The dependent variable is female labor force participation (FLFP) which is Dichotomous in nature, taking on a value $=1$ if a woman was working prior to the interview during the month of march 2020 when the pandemic broke out and zero otherwise. The sample includes all adult women above 18 years of age and where working or not working during the lockdown. We analyze the pre-COVID-19 employment status that is controlled for in all subsequent models. Robust standard errors are captured in the parentheses as $* * * \mathrm{p}<0.01, * * \mathrm{p}<0.05, * \mathrm{p}<0.1$ 
Table 3: The impact of COVID-19 lockdown on female labor market participation: with subgroups

\begin{tabular}{|c|c|c|c|c|c|c|c|c|}
\hline \multirow[b]{2}{*}{$\begin{array}{l}\text { Female labor force } \\
\text { participation (flfp) }\end{array}$} & \multicolumn{2}{|c|}{ By Children present } & \multicolumn{3}{|c|}{ By age of the women } & \multicolumn{3}{|c|}{ By highest level of education } \\
\hline & Children & $\begin{array}{l}\text { No } \\
\text { children }\end{array}$ & $18-30$ & $31-50$ & $51+$ & No school & Primary & $\begin{array}{l}\text { Post } \\
\text { primary }\end{array}$ \\
\hline Female locked & $\begin{array}{l}0.517 * * * \\
(0.146\end{array}$ & $\begin{array}{l}0.471^{*} \\
(0.261)\end{array}$ & $\begin{array}{l}0.522 * * \\
(0.213\end{array}$ & $\begin{array}{l}0.407 * \\
(0.219)\end{array}$ & $\begin{array}{l}0.753 * * * \\
(0.247)\end{array}$ & 0.000 & $\begin{array}{l}0.374^{* *} \\
(0.172)\end{array}$ & $\begin{array}{l}0.364^{*} \\
(0.208)\end{array}$ \\
\hline Male locked & $\begin{array}{l}0.665^{* * * *} \\
(0.229\end{array}$ & $\begin{array}{l}0.317 \\
(0.411)\end{array}$ & $\begin{array}{l}0.181 \\
(0.377)\end{array}$ & $\begin{array}{l}1.006 * * \\
(0.351)\end{array}$ & $\begin{array}{l}0.174 \\
(0.287)\end{array}$ & $\begin{array}{l}0.041 \\
(0.750)\end{array}$ & $\begin{array}{l}0.627^{* *} \\
(0.259)\end{array}$ & $\begin{array}{l}0.722 * * \\
(0.365)\end{array}$ \\
\hline Both locked & $\begin{array}{l}-1.122 * * * \\
(0.363)\end{array}$ & $\begin{array}{l}0.218 \\
(0.534)\end{array}$ & $\begin{array}{l}-0.357 \\
(0.529\end{array}$ & $\begin{array}{l}-1.341^{* *} \\
(0.518)\end{array}$ & $\begin{array}{l}-0.787^{*} \\
(0.440)\end{array}$ & $\begin{array}{l}-1.852^{*} \\
(0.996)\end{array}$ & $\begin{array}{l}-0.430 \\
(0.423)\end{array}$ & $\begin{array}{l}-1.034^{* *} \\
(0.523)\end{array}$ \\
\hline High threat & $\begin{array}{l}-1.184^{* * *} \\
(0.407)\end{array}$ & $\begin{array}{l}-0.627 \\
(0.631)\end{array}$ & $\begin{array}{l}-1.112 * * \\
(0.459)\end{array}$ & $\begin{array}{l}-0.474 \\
(0.547)\end{array}$ & $\begin{array}{l}-5.372 * * * \\
(0.407)\end{array}$ & $\begin{array}{l}-6.395^{* * *} \\
(0.783)\end{array}$ & $\begin{array}{l}-0.835^{* *} \\
(0.391)\end{array}$ & $\begin{array}{l}-1.469^{*} \\
(0.845)\end{array}$ \\
\hline Moderate threat & $\begin{array}{l}-1.019^{* *} \\
(0.410)\end{array}$ & $\begin{array}{l}0.081 \\
(0.654)\end{array}$ & $\begin{array}{l}-1.068^{* *} \\
(0.470)\end{array}$ & $\begin{array}{l}-0.085 \\
(0.545)\end{array}$ & $\begin{array}{l}-4.821 * * * \\
(0.445)\end{array}$ & $\begin{array}{l}-3.341 * * * \\
(1.024)\end{array}$ & $\begin{array}{l}-0.626 \\
(0.413)\end{array}$ & $\begin{array}{l}-1.234 \\
(0.853)\end{array}$ \\
\hline Own business & $\begin{array}{l}0.513^{* * *} \\
(0.140)\end{array}$ & $\begin{array}{l}1.080^{* * *} \\
(0.278)\end{array}$ & $\begin{array}{l}0.448 * * \\
(0.194)\end{array}$ & $\begin{array}{l}0.697 * * * \\
(0.208)\end{array}$ & $\begin{array}{l}0.838 * * * \\
(0.294)\end{array}$ & $\begin{array}{l}-0.166 \\
(0.963)\end{array}$ & $\begin{array}{l}0.629 * * * \\
(0.181)\end{array}$ & $\begin{array}{l}0.722 * * * \\
(0.188)\end{array}$ \\
\hline Home-schooling & $\begin{array}{l}0.037 \\
(0.151)\end{array}$ & $\begin{array}{l}0.259 \\
(0.243)\end{array}$ & $\begin{array}{l}-0.222 \\
(0.225)\end{array}$ & $\begin{array}{l}0.305 \\
(0.228)\end{array}$ & $\begin{array}{l}0.072 \\
(0.231)\end{array}$ & $\begin{array}{l}-1.620 * * \\
(0.810)\end{array}$ & $\begin{array}{l}0.204 \\
(0.185)\end{array}$ & $\begin{array}{l}0.151 \\
(0.199)\end{array}$ \\
\hline $\begin{array}{l}\text { Behavior change } \\
\text { Hand washing }\end{array}$ & $\begin{array}{l}0.680 * * * \\
(0.248)\end{array}$ & $\begin{array}{l}1.527^{* * * *} \\
(0.516)\end{array}$ & $\begin{array}{l}0.822 * * \\
(0.342)\end{array}$ & $\begin{array}{l}0.970 * * \\
(0.387)\end{array}$ & $\begin{array}{l}0.736^{*} \\
(0.455)\end{array}$ & $\begin{array}{l}-0.471 \\
(0.628)\end{array}$ & $\begin{array}{l}0.865^{* * *} \\
(0.269)\end{array}$ & $\begin{array}{l}1.481 * * * \\
(0.460)\end{array}$ \\
\hline Masks & $\begin{array}{l}0.094 \\
(0.259)\end{array}$ & $\begin{array}{l}1.153^{* *} \\
(0.559)\end{array}$ & $\begin{array}{l}0.379 \\
(0.378)\end{array}$ & $\begin{array}{l}0.143 \\
(0.409)\end{array}$ & $\begin{array}{l}0.235 \\
(0.467)\end{array}$ & 0.000 & $\begin{array}{l}0.133 \\
(0.289)\end{array}$ & $\begin{array}{l}1.052 * * \\
(0.488)\end{array}$ \\
\hline $\begin{array}{l}\text { Marital status } \\
\text { Married }\end{array}$ & $\begin{array}{l}0.160 \\
(0.244)\end{array}$ & $\begin{array}{l}-0.786^{* *} \\
(0.345)\end{array}$ & $\begin{array}{l}-0.061 \\
(0.347)\end{array}$ & $\begin{array}{l}0.507 \\
(0.367)\end{array}$ & $\begin{array}{l}-0.225 \\
(0.320)\end{array}$ & $\begin{array}{l}1.818^{* *} \\
(0.703)\end{array}$ & $\begin{array}{l}-0.206 \\
(0.273)\end{array}$ & $\begin{array}{l}0.623^{*} \\
(0.357)\end{array}$ \\
\hline Others & $\begin{array}{l}0.452^{*} \\
(0.261)\end{array}$ & $\begin{array}{l}-0.502 \\
(0.344)\end{array}$ & $\begin{array}{l}0.226 \\
(0.365)\end{array}$ & $\begin{array}{l}0.702^{*} \\
(0.394)\end{array}$ & $\begin{array}{l}0.374 \\
(0.356)\end{array}$ & $\begin{array}{l}2.698 * * * \\
(0.948)\end{array}$ & $\begin{array}{l}0.201 \\
(0.298)\end{array}$ & $\begin{array}{l}0.753 * * \\
(0.363)\end{array}$ \\
\hline Received assistance & $\begin{array}{l}0.182 \\
(0.420)\end{array}$ & $\begin{array}{l}-0.074 \\
(0.767)\end{array}$ & $\begin{array}{l}0.525 \\
(0.495)\end{array}$ & $\begin{array}{l}-0.843 \\
(0.726)\end{array}$ & $\begin{array}{l}0.889 \\
(0.707)\end{array}$ & 0.000 & $\begin{array}{l}1.248^{* *} \\
(0.516)\end{array}$ & $\begin{array}{l}-0.338 \\
(0.446)\end{array}$ \\
\hline Number o & 459 & 172 & 216 & 214 & 205 & 50. & 345 & 221 \\
\hline Mean dep & 0.669 & 0.663 & 0.639 & 0.682 & 0.688 & 0.700 & 0.719 & 0.593 \\
\hline SD dept variable & 0.471 & 0.474 & 0.481 & 0.467 & 0.465 & 0.463 & 0.450 & 0.492 \\
\hline Days of interview & Yes & Yes & Yes & Yes & Yes & Yes & Yes & Yes \\
\hline Worked pre-COVID & Yes & Yes & Yes & Yes & Yes & Yes & Yes & Yes \\
\hline Regional fixed effect & Yes & Yes & Yes & Yes & Yes & Yes & Yes & Yes \\
\hline HH \& women x-tics & Yes & Yes & Yes & Yes & Yes & Yes & Yes & Yes \\
\hline
\end{tabular}

Sources: probit output based on UHFS (2020)

Notes: FLFP is a dummy variable representing the female labor force participation, this was captured in the question as whether the women worked the previous week prior to the survey, it is a dichotomous (dummy) variable taking one 1 if YES and 0 if NO work. Working before the outcome is controlled for as a dummy variable for those who were working and 0 otherwise. We control for lockdown as a dummy variable captured by unemployed at home or working from home. The self-reported COVID-19 concern or threat captures financial or income stress to the individual. Figures in the buckets represent Robust standard errors and Level of significance displayed as $* * * \mathrm{p}<0.01$, $* * \mathrm{p}<0.05, * \mathrm{p}<0.1$

\section{Discussions}

We begin by looking at the preliminary results from table 2, here the coefficients are expressed in terms of marginal effects or the percentage points (pp.) change for the women either working or not working during 
the COVID-19 lockdown. From panel A1, there was a 7.1 percentage point's significant increase in the female labor force participation when only females were locked as opposed to a decrease of $13.6 \mathrm{pp}$ for those that did not work for those the same gender category. On the other hand, a 20 percentage points is observed among female workers if only the male partner is locked down as opposed to a decrease of 24.3 pp for if both partners are locked down. If we consider the self-reported COVID-19 threat to capture economic or financial anticipated stress, we see a significant decrease in in the female labor force participation for both those who though the pandemic posed a higher and moderate threat at $32.4 \mathrm{pp}$ and $25.3 \mathrm{pp}$ respectively as opposed those who thought it that it posed no threat at all. Considering those who either own or operate a family business the picture is no different for instance a 13.5 percentage point is observed among women who were either unemployed or worked from home. But we observe a decrease in female labor market activities if only the male partner is locked done. However their participation again raises by $6.3 \mathrm{pp}$ when both partners are locked, this can be explained by combined effort of both partners so as to look after the family, and this result may be against explanations put forward in partner violence related studies (see; Arenas-Arroyo, Fernandez-Kranz, and Nollenberger 2020). Labor market activity still significantly decreases for individuals who operated their own business and thought that the pandemic outbreak posed a high and moderate threat (33.9 and 35.8pp) respectively, results in column 5 of table 2 . The decrease in the labor activity for those who operated own business can be explained by the need to cut back on the costs and remain afloat during and even after the pandemic since business environment was unclear when the diseases started, a similar finding is found by (Balduzzi et al. 2020) in a study of the impact of the pandemic on Italian firms and business sector in general and in a global macroeconomic impact of COVID-19 study by (Mckibbin and Fernando 2020).

The results of this studies' main specification are captured in table 3 (results table), here we disaggregate, the impact the COVID-19 lockdown and its associated self-reported threat and concern, we also progressively incorporate other control covariates in the model as suggested in the model specification section. Needless to mention we control for employment status before COVID-19, education level of the partner, days of interview to capture the change in the people's attitudes and perceptions towards to the 
pandemic as it progressed, marital status, age of the women, receipt of assistance from any source, ownership of a business, home schooling to capture the demands on the mother's time allocation and behavioral change ( e.g. social distancing, hand washing and wearing of masks) in reference to the pandemic. Unlike other pandemic outbreaks like HIV/AIDS, Spanish influenza, Ebola and others, COVID19 demands immediate individual change and life adjustments for the successful fight against it.

Table 3 has a total of eight models from columns (2) to (9), here analysis is done for women with children, their age categories and their level of education, all of which critically not only affects female labor force participation but also the outcomes of the labor market such as wages and other earnings.

In columns (2) and (3), we analyze the impact of the presence of children on the female labor force participation, we see that the impact is highest when only the female partner is locked down, it impact ranges from as low as 47.1 to $51.7 \mathrm{pp}$, the COVID-19 threat causes an even greater effect on female labor market activity of a decrease of 18.4 and an increase of $62.7 \mathrm{pp}$ for those with and without children respectively, clearly female labor force activity significantly reduces for those with children, this can be explained by multiple demands on women's time during the lockdown such as engaging in household chores and children homeschooling. Conversely the impact of age on female labor force participation is highest when female parents are locked and this effect is significant for ages 18-30, 31-50 and 51 plus as seen from table 3. With reference to women's education level, higher impacts are reported when only the male parent is locked down, these effects range from 4.1, 62.7 and $72.2 \mathrm{pp}$ for women with No schooling, primary and post primary, here post primary includes, vocational certificates, diplomas, degree and higher.

Whereas the impact of business ownership or being own account worker is significantly high across all the estimated models among the controlled covariates (i.e. presence of children, age of the women, and educational level) for female labor force participation, the highest impacts can be seen among those aged 51 and above where effects increased by $83.8 \mathrm{pp}$. considering the impact of the presence of children, the impacts of owning a business on female labor force participation ranges a high of 51.3 to a low of 8 pp for women with and without children respectively. Considering education, the impact of owning a business on female labor force participation is highest among those post primary and primary education respectively 
(72.2 \& $62.9 \mathrm{pp}$ ). However, the impact decreases with No schooling. The impact of behavioral change (hand washing) on female labor force participation is highest among women with children compared to those with no children. This effect is significant at $1 \%$ level of significance in columns (2) and (3) in case of presence of children, columns (4-6) for age and (7) to (9) for education level of the women respectively. It is not surprising however, that those children had to adjust quickly to the SOPs in response to the pandemic outbreak not only to safeguard their families but also as a requirement for most employers and governments for workers to participate in the labor markets. For age the impact is highest among 31-50 year olds which is the most age category, but also those aged below 30 years suffer unprecedented levels of unemployment in Uganda.

Last but not least, we consider the impact of marital status of the women on FLFP we see significantly greater effects in column (2) for women in other categories of marital status (separated, widowed and divorced) with children. However, this significantly reduces among married women with no children by (78.6pp). Highly educated women that are either married or separated/widowed/divorced significantly participate in the labor market and this effects increase FLFP by $(62.3 \& 75.3 \mathrm{pp})$.

Lastly we move to test the impact of the COVID-19 government relief program on the female labor force participation during the lockdown, this is done by including a variable Received government assistance among the regression covariates as captured in UHFS questionnaire. We see an increase in FLFP among women with children by $18.2 \mathrm{pp}$ compared to a decrease of $7.4 \mathrm{pp}$ among those with no children. Taking receipt of government support as a measure of public health compliance with SOPs, some level of compliance can be reported among women with children and those with post primary education as shown in columns (3) and (9) respectively where FLFP reduces.

The limitation of this study could have been on predicted biases on the responses, this because the survey was carried out after the pandemic outbreak and the respondents intentionally could have under reported their incomes, inflated household sizes and missed reported their employment statuses in an anticipation of government supported 


\section{Conclusions}

Female labor force participation is of national and global concern with a potential to quickly evolve into a human rights violation and economic crisis for women if not address with utmost agency. The motivation for studying women's labor market activities is that women's work does not end in work places alone, it extends even to their homes (in terms of household chores and home schooling of children). This situation we anticipated was worsened by the lockdown needless to mention potential for domestic violence due to forced coexistence ${ }^{2}$. Using a first round of a monthly COVID-19 pandemic evolving data set, our results indicate bigger impacts for the pandemic outbreak on female labor participation, prevalence of female labor market activities drastically decline by $17 \%$ in the first months following strict shut down of the economy in the country. This situation is particularly worrying given the fact that most women in the country not only live hand to mouth, but also they are mostly employed in the informal sector. Thus it is important to incorporate in the analysis even unreported events. However, lockdown had a number of unintended consequences for instance income loss, increase in domestic violence, theft and other anti-social behaviors, political unrest and in the worst cases even death. Conceivably the only sanguine finding from our study is that extreme cases of lockdown i.e. when both partners are locked down female labor markets activities drastically reduce across all models in table 3. The reason for such a trend is unclear and thus leaves a vacuum to pose questions for future research in case of other pandemics.

In conclusion, easing of lockdown measures have not translated into faster increase in female labor market activities. Thus deliberate government effort should be devoted towards women who have children and those below the age of 30 and with no schooling, since we observe particularly greater impacts among this caste. Special attention should also be given to those who have lost their jobs or source of livelihood and those who were previously unemployed since the outbreak has hit them hardest.

\footnotetext{
${ }^{2}$ Similar results have been found in (Mckibbin and Fernando 2020)
} 


\section{List of Abbreviations and Acronyms}

COBAMS: College of Business \& Management Sciences 1

COVID-19: Coronavirus Disease 2019

FLFP: Female Labor Force Participation $\quad 9$

HC: Household Care/chores $\quad 9$

HIV/AIDS : Human Immunodeficiency Virus Infection and Acquired immune Deficiency Syndrome 6

IPV: Intimate Partner Violence $\quad 7$

LSMS: Living Standards Measurement Study $\quad 8$

MoH: Ministry of Health $\quad 4$

NCST: National Council of Science and Technology 16

PAS: Department of Planning \& Applied Statistics 1

PLD: Parent Locked down $\quad 9$

PP: Percentage Points 14

SARS: Severe acute respiratory syndrome $\quad 6$

UBOS: Uganda Bureau of Statistics 1

UHFS: Uganda High-frequency Phone Survey on COVID-19 1

$\begin{array}{lr}\text { UNPS: Uganda National Panel Survey } & 8\end{array}$

USAID: United States Agency for International Development $\quad 8$

WB: World Bank 16 


\section{Appendix}

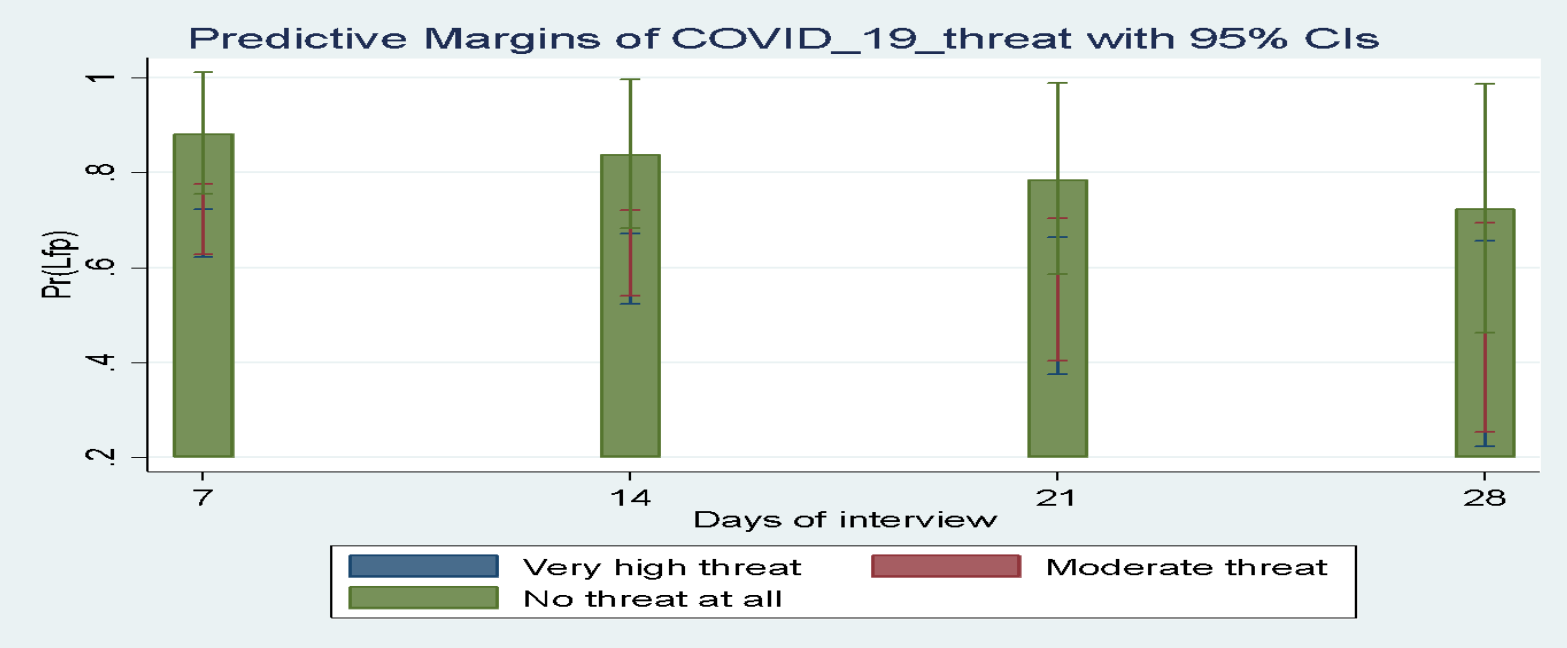

From the plunger plot above, it can clearly be observed that the predicted probability of female labor force participation was highest among those who thought that the pandemic posed no threat to their economic and social welfare, followed by those who thought the COVID-19 risk was moderate and those who reported a very high COVID-19 threat come in a third place at the pandemic progressed captured here in terms of the days of interview.

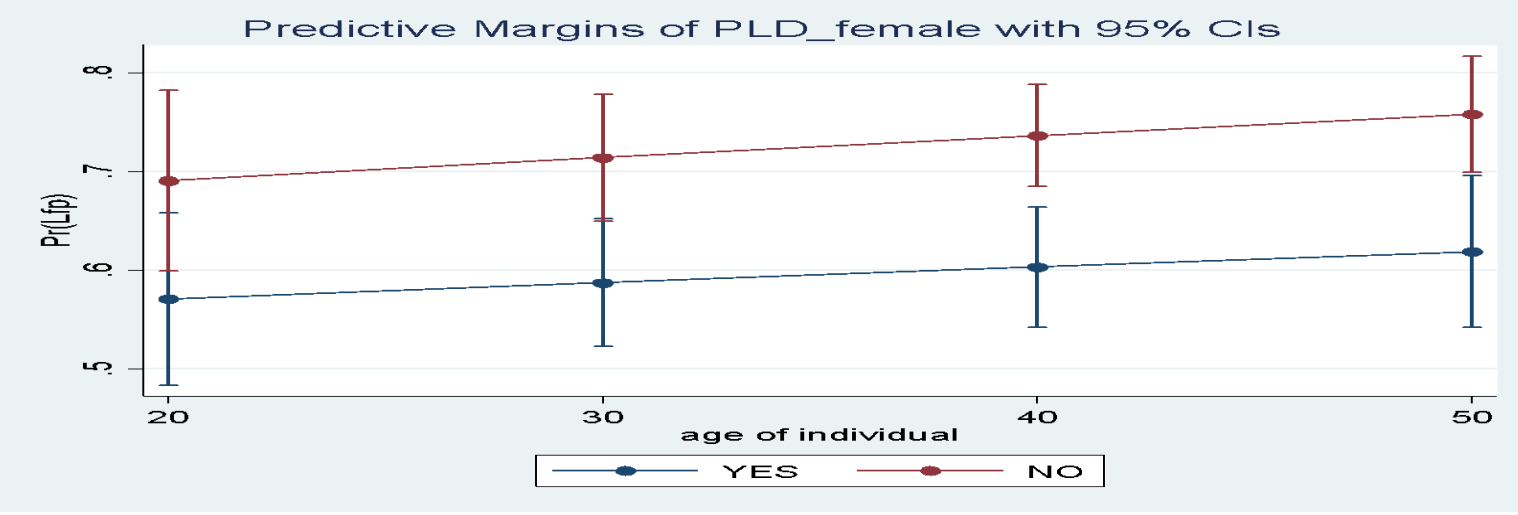

The predicted probability of female labor force participation during lockdown increases with one's age between those who were locked and those who were not locked during the COVID-19 outbreak. Here locked parents are those that were either unemployed at home or those that were working from home during the lockdown period, similar definitions have been used by (Arenas-Arroyo, Fernandez-Kranz, and Nollenberger 2020) in a study in Spain. 


\section{Declarations}

\section{Availability of data and materials}

The datasets utilized in this current study are available and can be accessed from the World Bank data repository (https://microdata.worldbank.org/index.php/catalog/3765)

\section{Ethics approval and consent to participate}

The present sought approval from the Uganda Bureau of Statistics being the custodians of the data set used for analysis, secondly the data is approved for public use and made publically available by the third party who is the World Bank (WB) in this case. In addition we sought approval from The Uganda National Council of Science and Technology (NCST) for Ethical consideration and a go head was given, since the data was made public by a third party.

\section{Consent for publication}

"Not applicable" the data about persons was made anonymous; there were no names that could pertain to the persons for their traceability. There is no person identification information in the dataset used and thus we could not trace people for their consent

\section{Availability of data and materials}

Data pertaining to the conclusions is available and it was downloaded from the World Bank website. Other additional datasets that support our results can be availed on result from the corresponding author.

\section{Competing interests}

There is no competing interest among the authors.

\section{Funding}

The funding of this study was obtained from Makerere University College of Business and management sciences under Institutional Paper writing project 2019/2020 phase one. No additional funding was gotten from anywhere. 


\section{Authors' contributions}

Mukoki James: Carried out Literature review and also conceptualized the idea under study, formulated the motivation for the study and also wrote the concept that was funded.

Candia Andabati: Carried out the data and other study related information gathering, did data cleaning, editing and other manipulations and analysis, he also carried out interpretation of results and other writeups.

Ssebulime Kurayish: Carried out final editing and formatting of the manuscript

Musoke Edward: carried out proofreading and further formatting and editing of the manuscript

\subsection{Acknowledgements}

We acknowledge the financial contribution from the College of Business and Management Science (COBAMS) of Makerere University and the Support and advice of Prof B. Yawe and also members of staff of School of statistics and PhD in Economics class of 2018.

\subsection{Authors' information}

$M J$ currently works as an Assistant Lecturer at School of Statistics and Planning (SSP) at Makerere University and also he is currently a PhD student at the School of Economics at Makerere University.

$C A D$, is an assistant Lecturer at the School of statistics of Makerere University and he is also a currently a $\mathrm{PhD}$ student in Social Statistics from University of Nairobi, he is an expert in the field of Biostatistics.

SK works as a senior labor Economics at the National Planning Authority (NPA) in Uganda and he is currently a PhD student of Economics from the school of Economics of Makerere University, He has a host of experience in the areas of labor economics.

$M E$ : currently works as an assistant lecturer at Makerere University. 


\section{Reference}

Angelucci, M., Angrisani, M., Bennett, D. M., Kapteyn, A., \& Schaner, S. G. Remote Work and the Heterogeneous Impact of COVID-19 on Employment and Health. National Bureau of Economic Research (No. w27749) (2020).

Arenas-Arroyo, E., Fernández-Kranz, D., \& Nollenberger, N. Can't Leave You Now! Intimate Partner Violence under Forced Coexistence and Economic Uncertainty. IZA, Institute of Labor Economics (2020).

Balduzzi, P., Brancati, E., Brianti, M., \& Schiantarelli, F. The Economic Effects of COVID-19 and Credit Constraints: Evidence from Italian Firms' Expectations and Plans. IZA, Institute of Labor Economics (2020)

Balleer, A., Link, S., Menkhoff, M., \& Zorn, P. Demand or supply? Price adjustment during the Covid-19 pandemic. IZA, Institute of Labor Economics (2020)

Becker, G. S. Human capital, effort, and the sexual division of labor. Journal of labor economics, 3(1, Part 2), S33-S58 (1985). URL : Http://Www.Jstor.Com/Stable/2534997

Berulava,G Chikava, G. “The Determinants of Household Labor Supply : A Comparative Study, Working paper No 11/13E (2015), URL : https://www.researchgate.net/publication/265237461

Gaudecker, Hans-Martin von et al. "Labour Supply during Lockdown and a 'New Normal ': The Case of the Netherlands" Institute of Labor Economics, IZA DP No. 13623 (2020).

Gershuny, Jonathan et al. "A New Perspective from Time Use Research on the Effects of Lockdown on COVID-19 Behavioral Infection Risk. Institute of Labor Economics, IZA DP No. 13599 (2020)

Goff, S., Ifcher, J., Zarghamee, H., Reents, A., \& Wade, P. The Effect of the COVID-19 Pandemic on Government-and Market-Attitudes. Institute of Labor Economics, IZA DP No.13622 (2020).

Arenas-Arroyo, Esther, Daniel Fernandez-Kranz, and Natalia Nollenberger. 2020. "DISCUSSION PAPER SERIES Can ' t Leave You Now! Intimate Partner Violence under Forced Coexistence and Economic Uncertainty Can' t Leave You Now! Intimate Partner Violence under Forced Coexistence and Economic Uncertainty." (13570).

UBOS. 2020. UGANDA HIGH-FREQUENCY PHONE SURVEY ON COVID-19 ROUND ONE. Kampala. https://www.ubos.org/publications/statistical/.

Arenas-Arroyo, Esther, Daniel Fernandez-Kranz, and Natalia Nollenberger. 2020. "DISCUSSION PAPER SERIES Can 't Leave You Now ! Intimate Partner Violence under Forced Coexistence and Economic 
Uncertainty Can' t Leave You Now! Intimate Partner Violence under Forced Coexistence and Economic Uncertainty.” (13570).

Lakuma, Corti Paul . et al. 2020. The Uganda Business Climate Index How Has the COVID-19 Pandemic Impacted Ugandan Businesses? Results from a Business Climate Survey. Kampala. https://eprcug.org/research/the-uganda-business-climate-index.

Mukiza, Chris Ndatira. 2020. Impact of COVID-19 on Key Economic Activities in Uganda and Suggested Policy Interventions. Kampala. http://www.npa.go.ug/current-development-issues/.

UBOS. 2020. UGANDA HIGH-FREQUENCY PHONE SURVEY ON COVID-19 ROUND ONE. Kampala. https://www.ubos.org/publications/statistical/.

https://www.uneca.org/sites/default/files/PublicationFiles/ eca-iec_survey_covid 19_africa_english_final.pdf 